\title{
miR-21 expression and clinical outcome in locally advanced pancreatic cancer: exploratory analysis of the pancreatic cancer Erbitux, radiotherapy and UFT (PERU) trial
}

\author{
Khurum Khan ${ }^{1}$, David Cunningham ${ }^{1}$, Clare Peckitt $^{1}$, Sarah Barton ${ }^{1}$, Diana Tait ${ }^{1}$, \\ Maria Hawkins ${ }^{1,2}$, David Watkins ${ }^{1}$, Naureen Starling ${ }^{1}$, Sheela Rao ${ }^{1}$, Ruwaida \\ Begum $^{1}$, Janet Thomas ${ }^{1}$, Jacqui Oates ${ }^{1}$, Vincenza Guzzardo ${ }^{3}$, Matteo Fassan ${ }^{3}$, \\ Chiara Braconi ${ }^{1,4}$ and Ian Chau ${ }^{1}$ \\ ${ }^{1}$ Gastrointestinal Unit, The Royal Marsden NHS Foundation Trust, Sutton, UK \\ ${ }^{2}$ CRUK/MRC Oxford Institute for Radiation Oncology. Gray Laboratories, University of Oxford, Oxford, UK \\ ${ }^{3}$ Department of Medicine, University of Padua, Padua, IT \\ ${ }^{4}$ Division of Cancer Therapeutics, The Institute of Cancer Research, Sutton, UK \\ Correspondence to: Chiara Braconi, email: Chiara.braconi@icr.ac.uk \\ Ian Chav, email: Ian.Chav@rmh.nhs.uk \\ Keywords: pancreatic cancer, microRNA, miR-21, chemo-radiotherapy, cetuximab \\ Received: November 27, 2015 Accepted: January 25, $2016 \quad$ Published: February 05, 2016
}

\section{ABSTRACT}

Background: Locally advanced pancreatic cancer (LAPC) is associated with high mortality, and biomarker-driven treatment approach is currently lacking. This study evaluated safety and efficacy of a combination approach of chemotherapy followed by chemo-radiotherapy (CRT) +/- cetuximab, and the prognostic role of miR-21 in patients with LAPC treated with a multimodality approach.

Patients and Methods: This was a randomised phase II trial in which patients with inoperable LAPC were offered gemcitabine and capecitabine (GEM-CAP) for 16 weeks. Patients with stable disease or response after GEM-CAP were randomised to capecitabine or UFT plus radiotherapy (RT) (A), or capecitabine or UFT plus cetuximab plus RT (B). The primary outcome of the study was overall survival (OS). Clinical outcome was compared according to baseline circulating miR-21 levels.

Results: 17 patients were enrolled and treated with GEM-CAP, with 13 patients achieving disease control and being randomised to arms $A(n: 7)$ and $B(n: 6)$. After a median follow-up of 61.2 months, median progression free survival (PFS) was $\mathbf{1 0 . 4}$ months and 12.7 months, median OS was 15.8 months and 22.0 months in arms $A$ and $B$ respectively $(p>0.05)$. Patients with high baseline plasma miR-21 had worse PFS (3.5 vs. 12.7 months; p:0.032) and OS (5.1 vs 15.3 months; p:0.5) compared to patients with low miR-21. Circulating miR-21 levels reflected miR-21 expression within the tissues.

Conclusions: Addition of Cetuximab to CRT following induction chemotherapy did not improve survival. High miR-21 baseline plasma expression was associated with poor clinical outcome in LAPC patients treated with induction chemotherapy followed by chemo-radiotherapy.

\section{INTRODUCTION}

Despite the recent advancements in diagnosis and management of solid malignancies, pancreatic ductal adenocarcinoma (PDAC) remains a highly lethal disease [1]. Majority of patients present with locally advanced unresectable (40-50\%) or metastatic disease (40\%) [2]. Management of Locally advanced Pancreatic Cancer (LAPC) remains largely under-researched with lack of evidence both in terms of optimal treatment approach and biomarkers that could inform such an approach [3]. Although previously conducted studies failed to 
demonstrate any definite survival advantage of chemoradiotherapy (CRT) over chemotherapy (CT) alone $[4,5]$, retrospective analysis of 4 phase II-III studies demonstrated that patients without disease progression after 3 months of CT, followed by CRT had a longer survival than those continuing on CT alone [6]. A pooled meta-analysis of SAKK and UK studies showed clinical activity for gemcitabine and capecitabine (GEMCAP) combination [7, 8], suggesting this could be considered a useful neo-adjuvant chemotherapy (NACT) approach. Recent evidence suggests that addition of epidermal growth factor receptor (EGFR) inhibition to CRT is feasible and promising in terms of efficacy [9]. Furthermore, EGFR is known to be upregulated in up to $69-95 \%$ of advanced pancreatic cancers $[10,11]$ and the EGFR tyrosine kinase inhibitor erlotinib combined with gemcitabine demonstrated survival benefit over gemcitabine alone [12]. Cetuximab, an anti-EGFR antibody has been safely combined with chemotherapy and radiotherapy in patients with LAPC and with other cancers [13-15]. Additionally, pre-clinical studies have demonstrated improved efficacy when gemcitabine was combined with radiotherapy in PDAC, suggesting independent radio-sensitive effects of cetuximab in this cancer $[16,17]$.

MicoRNAs (miRNAs) are non-coding RNAs that have been implicated in post-transcriptional regulation of gene expression. Growing evidence suggests the role of miRNAs in regulation of carcinogenesis and modulation of drug response [18, 19]. Over-expression of miR-21 is known to be associated with decreased sensitivity to gemcitabine in vitro and with poor clinical outcomes in retrospective clinical studies [20-23]. Furthermore, miRNAs can be detected both in tissue and plasma thus suggesting their role as potentially useful clinical biomarkers [24].

In this randomised phase II trial of patients with LAPC, we sought to evaluate an optimal radiosensitivity agent in patients who achieved disease control (DC) after neo-adjuvant GEM-CAP. The PERU trial was closed prematurely in June 2013 because the emergent data from LAP-07 study [25] failed to demonstrate any meaningful survival advantage with the use of CRT approach following first-line chemotherapy in LAPC. However, we have taken advantage of this cohort of patients by carrying out a preliminary study on the role of circulating miRNAs as prognostic biomarkers in LAPC. Despite growing evidence supporting the value of circulating miRNAs in predicting clinical outcome in cancer patients, most of the data is generated in retrospective and unselected populations, and data in prospective clinical trials are lacking. Here we report miR-21 plasma expression and its association with clinical outcomes in this prospective study of LAPC patients treated with a combination approach.

\section{RESULTS}

\section{Baseline characteristics}

Seventeen patients, all with de novo LAPC were enrolled and treated with NACT. Patients and tumour characteristics have been summarised in Table 1. Sixteen (93\%) patients received at least 3 cycles of NACT. Median relative dose intensity of gemcitabine was $76.2 \%$, while that of capecitabine was $89.6 \%$. Eighty-three percent of patients received the planned dose of RT (Supplementary Table 1).

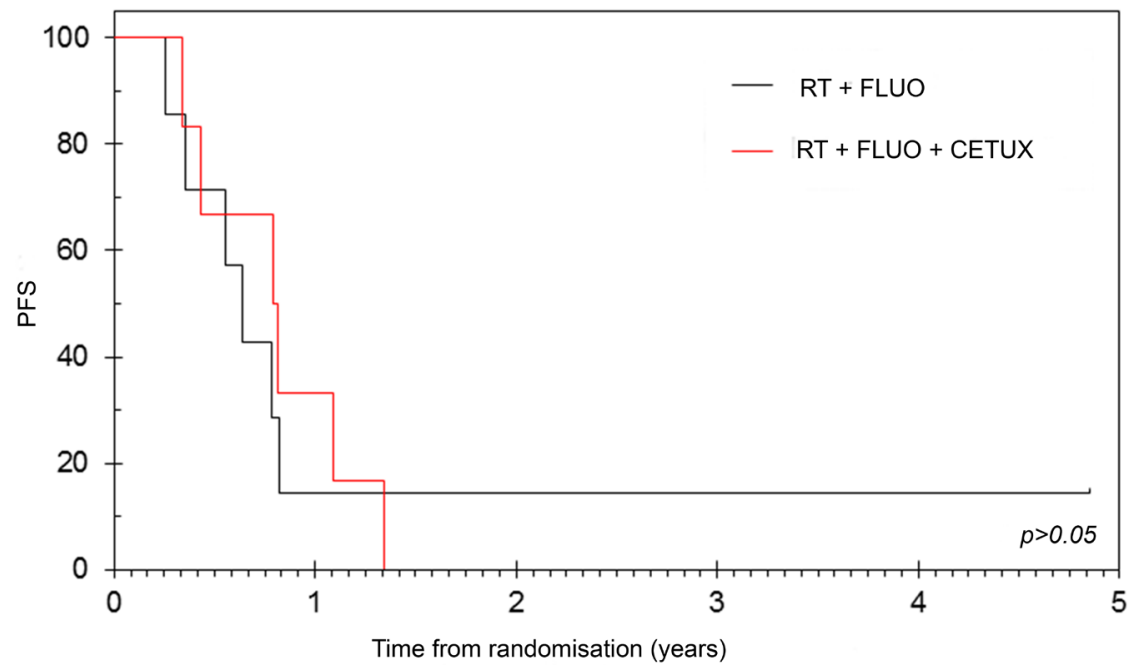

Figure 1: PFS according to randomisation. All randomised patients $(n=13)$ who achieved disease control with neoadjuvant chemotherapy were randomised to arms $\mathrm{A}(n=7)$ and $\mathrm{B}(n=6)$. After a median follow-up of 61.2 months, no differences in median PFS from randomization were observed between arm A [median 7.6 months (95\%CI: 5.1 - 10.3)] and arm B [median 9.5 months (95\%CI: 4.1 15.0)]. RT = radiotherapy, FLUO: Fluoropyrimidine and CETUX = cetuximab. 
Table 1: Clinico-pathological characteristics of all 17 registered patients receiving NACT

\begin{tabular}{|c|c|c|}
\hline & $\begin{array}{l}\mathbf{A L L} \\
N\end{array}$ & $(\%)$ \\
\hline $\begin{array}{c}\text { Age (years) } \\
\text { Median, (range) }\end{array}$ & $61.0(47-76)$ & \\
\hline $\begin{array}{l}\text { Gender } \\
\text { Male } \\
\text { Female }\end{array}$ & $\begin{array}{c}11 \\
6\end{array}$ & $\begin{array}{l}64.7 \\
35.3\end{array}$ \\
\hline $\begin{array}{c}\text { ECOG Performance Status } \\
0 \\
1\end{array}$ & $\begin{array}{c}3 \\
14\end{array}$ & $\begin{array}{l}17.7 \\
82.3\end{array}$ \\
\hline $\begin{array}{l}\text { Site of Primary } \\
\text { Head of Pancreas } \\
\text { Body of Pancreas }\end{array}$ & $\begin{array}{c}13 \\
4\end{array}$ & $\begin{array}{l}76.5 \\
23.5\end{array}$ \\
\hline $\begin{array}{c}\text { Radiological T-stage } \\
\text { T3 } \\
\text { T4 } \\
\text { TX }\end{array}$ & $\begin{array}{c}1 \\
13 \\
3\end{array}$ & $\begin{array}{l}5.9 \\
76.5 \\
17.6\end{array}$ \\
\hline $\begin{array}{c}\text { Radiological } N \text {-stage } \\
\text { N0 } \\
\text { N1 } \\
\text { NX }\end{array}$ & $\begin{array}{l}5 \\
9 \\
3\end{array}$ & $\begin{array}{l}29.4 \\
52.9 \\
17.6\end{array}$ \\
\hline
\end{tabular}

\section{Efficacy and safety}

Thirteen patients who achieved disease control rate $(\mathrm{DCR})$ with NACT $(\mathrm{PR}=11.8 \%, \mathrm{SD}=64.7 \%)$ were randomised to arms $\mathrm{A}(n=7)$ and $\mathrm{B}(n=6)$. Objective Response Rate (ORR) following CRT was $14.3 \%$ and $33.3 \%$ in groups A and B respectively $(p>0.05)$. After a median follow-up of 61.2 months, median Overall Survival (OS) from time of NACT was 15.8 (95\% CI: 14.5 - 17.9) and 22.0 (95\% CI: 0 - 45.5; $p>0.05)$ months while median Progression Free Survival (PFS) was found to be 10.4 (95\% CI: 7.8 - 13.0) and 12.7 (95\% CI: 7.3 - 18.0; $p>0.05$ ) months in the two arms respectively (Figure 1). 1-year survival was $100 \%$ and $66.7 \%(p=$

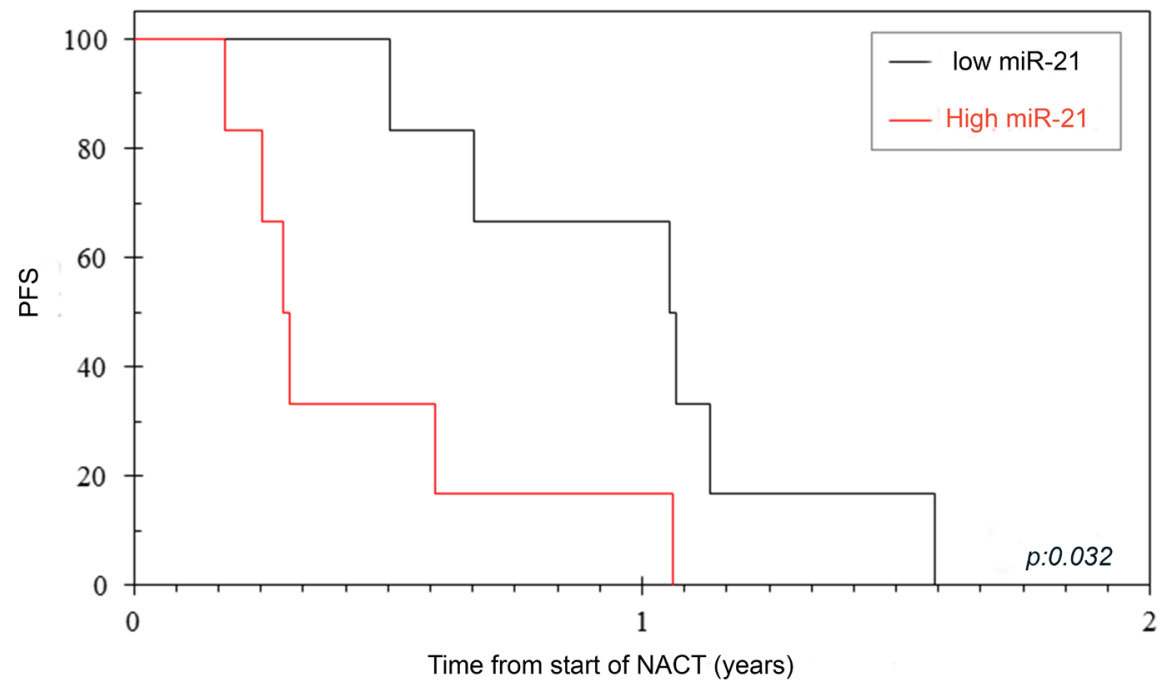

Figure 2: PFS according to miR-21 expression. Circulating miR-21 was assessed in baseline plasma and used as a binary variable to differentiate patients with high miR-21 and low miR-21. miR-21 expression significantly correlated with PFS. 
Table 2: Adverse events during chemo-radiation with or without cetuximab

\begin{tabular}{|c|c|c|c|c|}
\hline \multirow[t]{2}{*}{ TOXICITY } & \multicolumn{2}{|c|}{$\begin{array}{l}\text { CRT ARM A (RT+FLUO) } \\
(n=6)\end{array}$} & \multicolumn{2}{|c|}{$\begin{array}{l}\begin{array}{l}\text { CRT ARM B (RT + FLUO + CETUX) } \\
(n=6)\end{array} \\
\end{array}$} \\
\hline & $\begin{array}{c}\text { Grade I/II } \\
N(\%)\end{array}$ & $\begin{array}{c}\text { Grade III/IV } \\
\qquad(\%)\end{array}$ & $\begin{array}{c}\text { Grade I/II } \\
\quad N(\%)\end{array}$ & $\begin{array}{c}\text { Grade III/IV } \\
N(\%)\end{array}$ \\
\hline Anaemia & $3(50)$ & & $5(83.3)$ & \\
\hline Hyperglycaemia & $5(71.4)$ & & $4(66.7)$ & \\
\hline Hyponatraemia & $5(83.3)$ & $1(16.7)$ & $4(66.7)$ & \\
\hline Dry skin & $2(33.3)$ & & $4(66.7)$ & \\
\hline Constipation & & & $4(66.7)$ & \\
\hline Rash/desquamation & & & $4(66.7)$ & \\
\hline Thrombocytopenia & $4(66.7)$ & & $3(50)$ & \\
\hline Lethargy & $4(66.7)$ & & $3(50)$ & \\
\hline Hypocalcaemia & & & $3(50)$ & \\
\hline Hand foot syndrome (PPE) & $3(50)$ & & $2(33.3)$ & \\
\hline Diarrhoea & $5(83.3)$ & & $2(33.3)$ & \\
\hline Anorexia & $2(33.3)$ & & $2(33.3)$ & \\
\hline Nausea & $3(50)$ & & & \\
\hline Neutropenia & & & $2(33.3)$ & \\
\hline Fatigue & $1(14.2)$ & $1(16.7)$ & $2(33.3)$ & \\
\hline Hypokalaemia & & & $2(33.3)$ & \\
\hline Vomiting & $2(28.6)$ & & $1(16.7)$ & \\
\hline Abdominal pain & $1(16.7)$ & $1(16.7)$ & $1(16.7)$ & \\
\hline Dehydration & $2(33.3)$ & & & \\
\hline Non Neutropenic infection & $1(16.7)$ & & $1(16.7)$ & \\
\hline Urinary frequency & & & $1(16.7)$ & \\
\hline Allergic reaction & & & $1(16.7)$ & \\
\hline Dizziness & $1(16.7)$ & & $1(16.7)$ & \\
\hline Dyspepsia & $2(28.6)$ & & $1(16.7)$ & \\
\hline Dyspnoea & $1(16.7)$ & & $1(16.7)$ & \\
\hline Psoriasis & & & $1(16.7)$ & \\
\hline Acneiform rash & & & $1(16.7)$ & \\
\hline Hyper-pigmentation & & & $1(16.7)$ & \\
\hline Hypercalcaemia & $1(16.7)$ & & & \\
\hline Hyperkalaemia & $1(16.7)$ & & & \\
\hline Hypoglycaemia & $1(16.7)$ & & & \\
\hline Hypomagnesaemia & & & $1(16.7)$ & \\
\hline Nail changes & $1(16.7)$ & & & \\
\hline Peripheral oedema & $1(16.7)$ & & & \\
\hline Stomatitis & $1(16.7)$ & & & \\
\hline Syncope & $1(16.7)$ & & & \\
\hline Taste alteration & $1(16.7)$ & & & \\
\hline
\end{tabular}

Table 3: miR-21 expression and efficacy data in all registered patients

\begin{tabular}{|c|c|c|c|c|c|c|}
\hline & $\underset{\text { Number of }}{\text { events }}$ & $\begin{array}{c}\text { Number of } \\
\text { subjects }\end{array}$ & \begin{tabular}{|c|} 
Median Survival \\
(Months) \\
$(95 \% \mathrm{CI})$
\end{tabular} & $\begin{array}{c}1 \text { Year Survival } \\
(95 \% \mathrm{CI})\end{array}$ & $\begin{array}{c}\text { Hazard Ratio } \\
\text { (95\% CI) }\end{array}$ & $p$-value \\
\hline $\begin{array}{c}\text { (PFS) } \\
\text { Low miR-21 } \\
\text { High miR-21 } \\
\end{array}$ & $\begin{array}{l}6 \\
6 \\
\end{array}$ & $\begin{array}{l}6 \\
6 \\
\end{array}$ & $\begin{array}{r}12.7(6.9-18.4) \\
3.5(2.8-4.3)\end{array}$ & $\begin{array}{c}66.7(29.1-100) \\
16.7(0-46.5)\end{array}$ & $\begin{array}{c}1.0 \\
4.7(1.1-19.7)\end{array}$ & 0.032 \\
\hline $\begin{array}{c}\text { (OS) } \\
\text { Low miR-21 } \\
\text { High miR-21 }\end{array}$ & $\begin{array}{l}6 \\
5\end{array}$ & $\begin{array}{l}6 \\
6\end{array}$ & $\begin{array}{c}15.3(7.3-23.3) \\
5.1(0-10.7)\end{array}$ & $\begin{array}{c}83.3(53.5-100) \\
33.3(0-70.9)\end{array}$ & $\begin{array}{c}1.0 \\
1.46(0.41-5.21)\end{array}$ & 0.564 \\
\hline
\end{tabular}


0.801, 95\% CI: 29.1 - 100) in arms A and B respectively. OS in all registered patients $(n=17)$ was 15.3 months (95\% CI: 13.0 - 17.5) and 64.7\% (95\% CI: 42.0 - 87.4) of the patients were alive at 1-year. NACT approach with GEM-CAP and combining cetuximab with CRT or with chemotherapy were both found to be safe (Table 2 and Supplementary Table 2).

\section{miR-21 molecular analysis results}

Of the 17 registered patients, plasma samples were available in 16 cases. Four cases could not be analysed because haemolysis occurred in the samples. Circulating
miR-21 expression was assessed by Taqman assay in the baseline plasma sample in 12 patients, who were divided in two groups (low and high miR-21) by using the median as a cut-off. When miR-21 expression was validated by digital droplet polymerase chain reaction (ddPCR), patients were assigned to the same groups (copies of $\mathrm{miR}-21 / \mathrm{ml}$ of plasma ranged between $1.1 \mathrm{E}+04$ and $1.4 \mathrm{E}+08)$. All these patients underwent NACT with GEM-CAP. Amongst these patients, 3 patients progressed on NACT, and 8 were further randomized to $\operatorname{arm~A~(~} n=$ $4)$ and arm B $(n=4)$. DCR post NACT was $100 \% v s$. $40 \%$ in patients with low and high miR-21 respectively $(p=0.06)$. Interestingly, all patients who progressed after NACT had high values of circulating miR-21 at

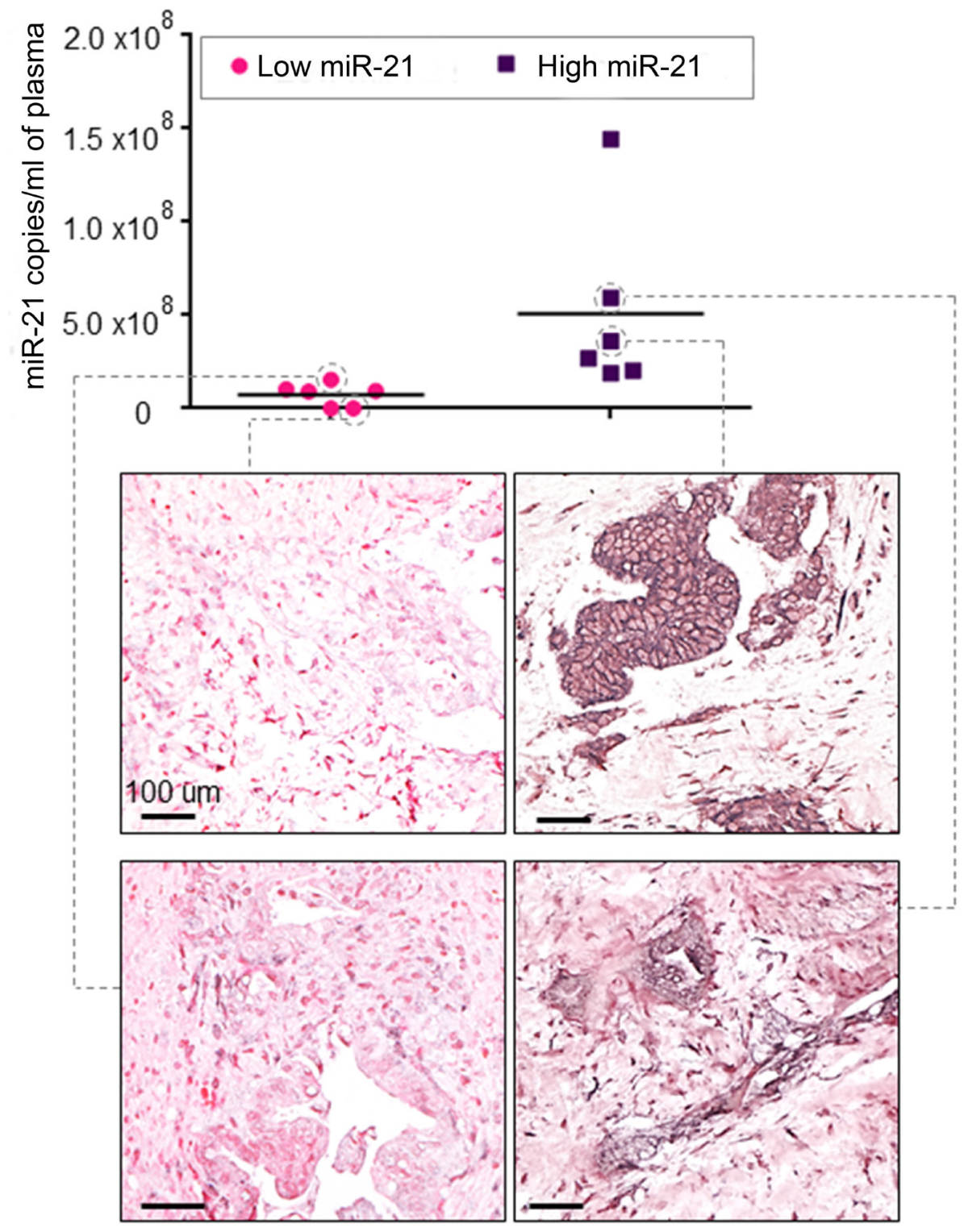

Figure 3: Circulating miR-21 expression reflects expression of miR-21 in tumour tissue. Matched baseline plasma and Formalin-Fixed-Paraffin-Embedded tissues were analysed. Circulating miR-21 expression was quantitated by ddPCR, and tissue miR-21 expression was assessed by ISH. Patients with high circulating levels of miR-21 had tumours with high miR-21 expression in cancer cells in the tissues. 
baseline (Supplementary Table 3). Patients with high miR-21 plasma levels had a significantly worse PFS from registration [3.5 (95\% CI: 2.8 - 4.3) vs. 12.7 (95\% CI: 6.9 - 18.4 months); $p=0.032]$, and a non-significant trend on OS was observed (Figure $2 \&$ Table 3 ). When all randomised patients were analysed, patients with low miR-21 were found to have better DCR at 6 weeks of chemotherapy $[100 \%(5 / 5)$ vs. $50 \%(1 / 2)]$ and better PFS (9.5 vs. 4.2 months). In order to investigate if circulating levels of miR-21 reflected expression of miR-21 in the primary tumour, we assessed miR-21 expression by In Situ Hybridization (ISH) in PDAC tissues. Matched baseline PDAC tissue was retrieved in 4 cases. Interestingly, miR21 expression was negative in tumours of patients with low circulating miR-21, while moderate to strong miR-21 expression was detected in tumour cells of patients with high circulating miR-21 (Figure 3).

\section{DISCUSSION}

Genetic heterogeneity is common in PDAC and limits the efficacy benefits gained from conventional anticancer therapies [23]. A significant proportion of patients presents with LAPC, where treatment approach is less well defined. The role of radiotherapy in management of LAPC remains a debatable issue. Induction chemotherapy is often used to better identify tumours that are already associated with micro-metastatic disease and are unlikely to benefit from localised treatments. Recent data from the LAP-07 trial suggested that CRT following NACT may improve quality of life by prolonging the time without treatment and reducing the risk of local progression, despite no impact on OS. The CirCe 07 translational ancillary study to the LAP-07 suggested that specific biomarkers, such as positivity of Circulating Tumour Cells (CTC) at baseline, could define patients with worse OS [26]. However, CTC positivity was not associated with improvement in PFS from CRT suggesting that further investigations are required in this field. A retrospective analysis of LAPC treated by CRT or CT alone suggested that molecular biomarkers, such as copy number variation of ACTN4 can better select patients who benefit from CRT over CT alone [27]; however, prospective validation of such findings remains sparse in the literature.

In this study we present data from a prospective clinical study of CRT following NACT that evaluated the role of miR-21, which is known to be associated with pancreatic carcinogenesis $[22,28]$. miR-21 is known to be highly over-expressed in PDAC and has a known association with tumour aggressiveness and poor clinical outcome [29-31]. Plasma levels of miR-21 were found to be elevated in PDAC patients compared to healthy controls [32]. We have previously shown that miR-21 modulates response to Fluorouracil (FU) [33]. miR21 was found to be an independent prognostic factor in unselected cohorts of PDAC patients undergoing GEM- based palliative or FU-based adjuvant chemotherapy [34-35]. To our knowledge, our study is the first study to demonstrate the potential prognostic role of circulating miR-21 in a prospective cohort of patients with LAPC. Despite the small numbers in our series, we were able to show that patients with low expression of miR-21 benefit more from chemotherapy with GEM-CAP and have a prolonged PFS when radiotherapy is combined to NACT. Lack of association of low miR-21 with improved OS is likely to be related to differences in subsequent palliative treatments and small sample size. PDAC shows high cellular heterogeneity and source of circulating miR21 can either be represented by tumour cells or stromal cells. Recent evidence suggests that miR-21 within the cancer associated fibroblasts can predict response to drug treatment more than cancer cell-derived miR-21. In order to investigate the source of circulating miR21 in our series, we assessed miR-21 expression in the matched tissues collected at the same time of the plasma collection. Although numbers are too low to draw definite conclusions, our study is a proof of concept that free plasma miR-21 reflects the expression of miR-21 in the cancer cells and therefore can be used as a surrogate for tumoural miR-21.

Our data support the notion that altered expression of plasma miR-21 may be a prognostic biomarker that may help to guide multi-modality treatment in LAPC. Acknowledging the limitations of our study in terms of small numbers, we believe that this analysis explores the role of the miR-21 in a prospective cohort of LAPC and provides further rationale for expanding biomarkerbased studies in PDAC. Based on our findings, miR-21 appears to have prognostic role in patients with LAPC. Moreover, our clinical data suggest that treatment with more efficacious contemporary NACT regimens may provide enhanced systemic control prior to consideration of localised therapy options such as radiotherapy, and thus may optimise outcomes. This approach may be particularly relevant in patients with low miR-21 expression, where better outcomes can be potentially expected. Further studies to elucidate the mechanisms by which miR-21 may increase tumour sensitivity to therapies are warranted.

\section{PATIENTS AND METHODS}

\section{Patients}

Eligible patients had histologically confirmed unresectable LAPC and had a World Health Organisation performance status (PS) of 0-2. Patients were considered unresectable based on at least one of the three features including a) extensive peri-pancreatic lymph node involvement, b) encasement/occlusion of the superior mesenteric vein (SMV) or SMV/portal vein confluence or 
c) direct involvement of superior mesenteric artery, coeliac axis, inferior vena cava or aorta. Patients who received prior chemotherapy and those with CT scan-evidence of metastatic disease were not allowed. All patients were required to have adequate bone marrow, liver and renal functions as defined by the study protocol.

\section{Study}

Pancreatic Cancer Erbitux, Radiotherapy and UFT (PERU) (ISRCTN: 65518365) was a randomised phase II study of neo-adjuvant GEM-CAP for 16 weeks in patients with LAPC. Gemcitabine $1000 \mathrm{mg} / \mathrm{m} 2$ was given as an intravenous (i.v.) infusion over 30 minutes and was administered on days 1,8 and 15 in a 28 day cycle. Capecitabine $1660 \mathrm{mg} / \mathrm{m} 2$ daily (in two divided doses) was administered orally for 21 days followed by 7 days' rest.

Following NACT, patients were randomised between: A) UFT/LV or capecitabine plus radiotherapy (RT) or B) UFT/LV or capecitabine plus cetuximab plus RT. Capecitabine $1600 \mathrm{mg} / \mathrm{m} 2 /$ day was given concomitanlty with RT alone in arm A or with i.v. Cetuximab $(400 \mathrm{mg} / \mathrm{m} 2$ on day 1 and $250 \mathrm{mg} / \mathrm{m} 2$ subsequently,weekly for 5 weeks) in arm B.

The aim of this study was to assess overall survival (OS) of patients receiving CRT or CRT + cetuximab after NACT. The primary endpoint of PERU study was 1-year OS; secondary end points included progression free survival (PFS), objective response rate (ORR), biomarkers of clinical benefit. The study had a Data Monitoring Committee (DMC) which monitored efficacy and safety on the study.

\section{Radiotherapy quality assurance}

RT (45Gy in 25 fractions) was given to tumour bed including involved nodes and tumour margins, followed by a boost to gross tumour volume (GTV) of 9 Gy in 5 fractions (5.4 Gy in 3 fractions was accepted as boost if normal tissue tolerance was exceeded). CT planning scan was performed between weeks 13 to 16 of NACT. Patients were treated using a 3D conformal technique; the $95 \%$ isodose was required to cover the planning target volume (PTV). GTV was defined by contrast enhanced CT and consisted of tumour and any enhancing lymph nodes $>$ $5 \mathrm{~mm}$ in the typical pancreatic drainage basin. No elective nodal irradiation was performed. The boost consisted of macroscopic visible disease with a $5 \mathrm{~mm}$ margin in all directions.

\section{Statistical analysis}

Based on the pooled GERCOR studies, the lower limit of $95 \%$ confidence interval (CI) for the 1-year survival rate of chemotherapy alone group was estimated to be $35 \%$. A 1 -year OS rate from the time of registration of $\geq 55 \%$ was considered acceptable (p1) and a 1-year OS rate from the time of registration of $<35 \%$ was estimated to be ruled out as unacceptable (p0). Giving 10\% drop out rate, a total of 45 patients per arm ( 90 patients in total) were to be randomised to reach 2-sided $\alpha=0.05$ and $80 \%$ power. However, the trial was closed pre-maturely, following emergent data from LAP-07 [25] study failing to demonstrate survival advantage with the use of NACT followed by CRT. This decision was endorsed by DMC.

Intention to Treat (ITT) population and safety population were defined as all patients who got randomised to a treatment arm as they had omplete response (CR), partial response (PR) or stable disease (SD) after 12 weeks of beginning NACT and had at least one post treatment visit. Patients were analysed as randomised. OS and PFS were calculated using Kaplan Meier in association with long-rank test for the two arms in the ITT population. 1-year OS rate was displayed with $95 \%$ CIs.

\section{Molecular analysis}

Baseline whole blood was collected in EDTAtreated tubes; cells were removed by centrifugation for 15 minutes at $1,500 \mathrm{x} \mathrm{g}$ using a refrigerated centrifuge $\left(4^{\circ} \mathrm{C}\right)$. Supernatant was collected and centrifuged for further 10 minutes at $1,500 \mathrm{x} \mathrm{g}$ at $4 \mathrm{C}$. The resulting supernatant was designated plasma and was transferred into clean RNAse free tubes and stored at -80. RNA was extracted from $200 \mathrm{uL}$ using the miRCURY RNA isolation kit (Exiqon, Denmark) following supplier instructions. Fixed starting volume was maintained for each sample. $2 \mathrm{ul}$ of RNA was then reverse transcribed and assessed for miR-21 expression (Taqman, Lifetechnologies, Paisley UK, code 000397). In the Kaplan Meier analysis, patients were divided in two groups: low miR-21 and high miR-21 according to median value. Validation by digital droplet PCR (Biorad, Berkeley, CA, USA) was performed as previously described [36]. A no template control and a negative control for each reverse transcription reaction were included in every assay and at least 10000 droplets were assessed for each sample. miR-21 expression was assessed blinded to clinical data.

miR-21 was assessed in tissue by RNA In Situ Hybridization (ISH). A locked nucleic acid (LNA) probe with complementarity to miR-21 was labeled with 5 '-digoxigenin and synthesized by Exiqon (Denmark), and ISH performed as previously described [37].

Given the lack of activity of Cetuximab we have pooled the two arms together and analysed OS and PFS by above/below median miR-21 value by Cox regression to obtain $95 \%$ CIs. 


\section{ACKNOWLEDGMENTS}

This work was supported by the National Institute for Health Research (NIHR) Biomedical Research Centre (BRC) at the Royal Marsden NHS Foundation Trust and Institute of Cancer Research, from the Research Innovation Fund from Pancreatic Cancer UK and Career Integration Grant from European Union (C.B), and the Robert McAlpine Charity (K.K.).

\section{CONFLICTS OF INTEREST}

The authors have declared no conflicts of interest.

\section{GRANT SUPPORT}

This work was supported by the National Institute for Health Research (NIHR) Biomedical Research Centre (BRC) at the Royal Marsden NHS Foundation Trust and Institute of Cancer Research, from the Research Innovation Fund from Pancreatic Cancer UK and Career Integration Grant from European Union (C.B), and the Robert McAlpine Charity (K.K.).

\section{Editorial note}

This paper has been accepted based in part on peerreview conducted by another journal and the authors' response and revisions as well as expedited peer-review in Oncotarget.

\section{REFERENCES}

1. Siegel R, Ma J, Zou Z, et al. Cancer statistics, 2014. CA: a cancer journal for clinicians. 2014; 64:9-29.

2. Willett CG, Czito BG, Bendell JC, Ryan DP. Locally advanced pancreatic cancer. J Clin Oncol. 2005; 23:453844.

3. Yip D, Karapetis C, Strickland A, Steer CB, Goldstein D. Chemotherapy and radiotherapy for inoperable advanced pancreatic cancer. Cochrane Database Syst Rev. 2006; CD0020933; 1-83.

4. Sultana A, Tudur Smith C, Cunningham D, Starling N, Tait D, Neoptolemos JP, Ghaneh P. Systematic review, including meta-analyses, on the management of locally advanced pancreatic cancer using radiation/combined modality therapy. Br J Cancer. 2007; 96:1183-90.

5. Chauffert B, Mornex F, Bonnetain F, Rougier P, Mariette C, Bouché O, Bosset JF, Aparicio T, Mineur L, Azzedine A, Hammel P, Butel J, Stremsdoerfer N, et al. Phase III trial comparing intensive induction chemoradiotherapy (60 Gy, infusional 5-FU and intermittent cisplatin) followed by maintenance gemcitabine with gemcitabine alone for locally advanced unresectable pancreatic cancer. Definitive results of the 2000-01 FFCD/SFRO study. Ann Oncol. 2008; 19:1592-9.

6. Huguet F, Andre T, Hammel P, tru P, Balosso J, Selle F, Deniaud-Alexandre E, Ruszniewski P, Touboul E, Labianca $\mathrm{R}$, de Gramont A, Louvet C. Impact of chemoradiotherapy after disease control with chemotherapy in locally advanced pancreatic adenocarcinoma in GERCOR phase II and III studies. J Clin Oncol. 2007; 25:326-31.

7. Herrmann R, Bodoky G, Ruhstaller T, Glimelius B, Bajetta E, Schüller J, Saletti P, Bauer J, Figer A, Pestalozzi B, Köhne CH, Mingrone W, Stemmer SM, et al. Gemcitabine plus capecitabine compared with gemcitabine alone in advanced pancreatic cancer: a randomized, multicenter, phase III trial of the Swiss Group for Clinical Cancer Research and the Central European Cooperative Oncology Group. J Clin Oncol. 2007; 25:2212-7.

8. Cunningham D, Chau I, Stocken DD, Valle JW, Smith D, Steward W, Harper PG, Dunn J, Tudur-Smith C, West J, Falk S, Crellin A, Adab Fet al. Phase III randomized comparison of gemcitabine versus gemcitabine plus capecitabine in patients with advanced pancreatic cancer. $\mathrm{J}$ Clin Oncol. 2009; 27:5513-8.

9. van Zweeden AA, van der Vliet HJ, Wilmink JW, Meijerink MR, Meijer OW, Bruynzeel AM, van Tienhoven G, Giovannetti E, Kazemier G, Jacobs MA, Verheul HM. Phase I clinical trial to determine the feasibility and maximum tolerated dose of panitumumab to standard gemcitabine-based chemoradiation in locally advanced pancreatic cancer. Clin Canc Res. 2015; 21:4569-75.

10. Xiong HQ, Rosenberg A, LoBuglio A, Schmidt W, Wolff RA, Deutsch J, Needle M, Abbruzzese JL. Cetuximab, a monoclonal antibody targeting the epidermal growth factor receptor, in combination with gemcitabine for advanced pancreatic cancer: a multicenter phase II Trial. J Clin Oncol. 2004; 22:2610-6.

11. Bloomston M, Bhardwaj A, Ellison EC, Frankel WL. Epidermal growth factor receptor expression in pancreatic carcinoma using tissue microarray technique. Dig Surg. 2006; 23:74-9.

12. Moore MJ, Goldstein D, Hamm J, Figer A, Hecht JR, Gallinger S, Au HJ, Murawa P, Walde D, Wolff RA, Campos D, Lim R, Ding Ket al. Erlotinib plus gemcitabine compared with gemcitabine alone in patients with advanced pancreatic cancer: a phase III trial of the National Cancer Institute of Canada Clinical Trials Group. J Clin Oncol. 2007; 25:1960-6.

13. Crane CH, Varadhachary GR, Yordy JS, Staerkel GA, Javle MM, Safran H, Haque W, Hobbs BD, Krishnan S, Fleming JB, Das P, Lee JE, Abbruzzese JLet al. Phase II trial of cetuximab, gemcitabine, and oxaliplatin followed by chemoradiation with cetuximab for locally advanced (T4) pancreatic adenocarcinoma: correlation of Smad4(Dpc4) immunostaining with pattern of disease progression. J Clin Oncol. 2011; 29:3037-43.

14. Bonner JA, Harari PM, Giralt J, Azarnia N, Shin DM, 
Cohen RB, Jones CU, Sur R, Raben D, Jassem J, Ove R, Kies MS, Baselga J et al. Radiotherapy plus cetuximab for squamous-cell carcinoma of the head and neck. N Engl J Med. 2006; 354:567-78.

15. Hofheinz RD, Horisberger K, Woernle C, Wenz F, KrausTiefenbacher U, Kähler G, Dinter D, Grobholz R, Heeger S, Post S, Hochhaus A, Willeke F. Phase I trial of cetuximab in combination with capecitabine, weekly irinotecan, and radiotherapy as neoadjuvant therapy for rectal cancer. Int $\mathrm{J}$ Radiat Oncol Biol Phys. 2006; 66:1384-90.

16. Kimple RJ, Vaseva AV, Cox AD, Baerman KM, Calvo BF, Tepper JE, Shields JM, Sartor CI. Radiosensitization of epidermal growth factor receptor/HER2-positive pancreatic cancer is mediated by inhibition of Akt independent of ras mutational status. Clini Canc Res. 2010; 16:912-23.

17. Morgan MA, Parsels LA, Kollar LE, Normolle DP, Maybaum J, Lawrence TS. The combination of epidermal growth factor receptor inhibitors with gemcitabine and radiation in pancreatic cancer. Clin Cancer Res. 2008; 14:5142-9.

18. Braconi C, Valeri N, Gasparini P, Huang N, Taccioli C, Nuovo G, Suzuki T, Croce CM, Patel T.Hepatitis $\mathrm{C}$ virus proteins modulate microRNA expression and chemosensitivity in malignant hepatocytes. Clin Canc Res. 2010; 16:957-66.

19. Osada H, Takahashi T. MicroRNAs in biological processes and carcinogenesis. Carcinogenesis. 2007; 28:2-12.

20. Hwang JH, Voortman J, Giovannetti E, Steinberg SM, Leon LG, Kim YT, Funel N, Park JK, Kim MA, Kang GH, Kim SW, Del Chiaro M, Peters GJ, Giaccone G. dentification of microRNA-21 as a biomarker for chemoresistance and clinical outcome following adjuvant therapy in resectable pancreatic cancer. PloS one. 2010; 5:e10630.

21. Giovannetti E, Funel N, Peters GJ, Del Chiaro M, Erozenci LA, Vasile E, Leon LG, Pollina LE, Groen A, Falcone A, Danesi R, Campani D, Verheul HM, Boggi U. MicroRNA-21 in pancreatic cancer: correlation with clinical outcome and pharmacologic aspects underlying its role in the modulation of gemcitabine activity. Canc Res. 2010; 70:4528-38.

22. Frampton AE, Castellano L, Colombo T, Giovannetti E, Krell J, Jacob J, Pellegrino L, Roca-Alonso L, Funel N, Gall TM, De Giorgio A, Pinho FG, Fulci V, et al. MicroRNAs cooperatively inhibit a network of tumor suppressor genes to promote pancreatic tumor growth and progression. Gastroenterology. 2014; 146:268-77.

23. Garajova I, Le Large TY, Frampton AE, Rolfo C, Voortman J, Giovannetti E. Molecular mechanisms underlying the role of microRNAs in the chemoresistance of pancreatic cancer. BioMed Res Int. 2014; 2014:678401.

24. Kanehisa M, Goto S, Furumichi M, Tanabe M, Hirakawa M. KEGG for representation and analysis of molecular networks involving diseases and drugs. Nucleic Acids Res. 2010; 38:D355-60.
25. Hammel P, Van Laethem JF, Goldstein D. Comparison of chemoradiotherapy (CRT) and chemotherapy (CT) in patients with a locally advanced pancreatic cancer (LAPC) controlled after 4 months of gemcitabine with or without erlotinib: Final results of the of the international phase III LAP 07 study. J Clin Oncol. 2013 (suppl; abstr LBA4003).

26. Bidard FC, Huguet F, Louvet C, Mineur L, Bouché O, Chibaudel B, Artru P, Desseigne F, Bachet JB, Mathiot C, Pierga JY, Hammel P.Circulating tumor cells in locally advanced pancreatic adenocarcinoma: the ancillary CirCe 07 study to the LAP 07 trial. Ann Oncol. 2013; 24:2057-61.

27. Watanabe T, Ueno H, Watabe Y, Hiraoka N, Morizane C, Itami J, Okusaka T, Miura N, Kakizaki T, Kakuya T, Kamita M, Tsuchida A, Nagakawa Y et al. ACTN4 copy number increase as a predictive biomarker for chemoradiotherapy of locally advanced pancreatic cancer. Brit J Canc. 2015; 112:704-13.

28. Vychytilova-Faltejskova P, Kiss I, Klusova S, Hlavsa J, Prochazka V, Kala Z, Mazanec J, Hausnerova J, Kren L, Hermanova M, Lenz J, Karasek P, Vyzula R, Slaby O. MiR-21, miR-34a, miR-198 and miR-217 as diagnostic and prognostic biomarkers for chronic pancreatitis and pancreatic ductal adenocarcinoma. Diagn Pathol. 2015; 10:38.

29. Dillhoff M, Liu J, Frankel W, Croce C, Bloomston M. MicroRNA-21 is overexpressed in pancreatic cancer and a potential predictor of survival. J Gastrointest Sur. 2008; 12:2171-6.

30. Jamieson NB, Morran DC, Morton JP, Ali A, Dickson EJ, Carter CR, Sansom OJ, Evans TR, McKay CJ, Oien KA. MicroRNA molecular profiles associated with diagnosis, clinicopathologic criteria, and overall survival in patients with resectable pancreatic ductal adenocarcinoma. Clin Canc Res. 2012; 18:534-45.

31. Frampton AE, Krell J, Jamieson NB Gall TM, Giovannetti E, Funel N, Mato Prado M, Krell D, Habib NA, Castellano L, Jiao LR, Stebbing J. microRNAs with prognostic significance in pancreatic ductal adenocarcinoma: A metaanalysis. Eur J Cancer. 2015; 51:1389-404.

32. Abue M, Yokoyama M, Shibuya R, Tamai K, Yamaguchi K, Sato I, Tanaka N, Hamada S, Shimosegawa T, Sugamura $\mathrm{K}$, Satoh K. Circulating miR-483-3p and miR-21 is highly expressed in plasma of pancreatic cancer. Int J Oncol. 2015; 46:539-47.

33. Valeri N, Gasparini P, Braconi C, Paone A, Lovat F, Fabbri M, Sumani KM, Alder H, Amadori D, Patel T, Nuovo GJ, Fishel R, Croce CM. MicroRNA-21 induces resistance to 5-fluorouracil by down-regulating human DNA MutS homolog 2 (hMSH2). Proc Natl Acad Sci USA. 2010; 107:21098-103.

34. Wang P, Zhuang L, Zhang J, Fan J, Luo J, Chen H, Wang K, Liu L, Chen Z, Meng Z. The serum miR-21 level serves as a predictor for the chemosensitivity of advanced pancreatic cancer, and miR-21 expression confers chemoresistance by targeting FasL. Molec Oncol. 2013; 7:334-45. 
35. Donahue TR, Nguyen AH, Moughan J, Tatishchev S, Toste P, Farrell JJ. Stromal microRNA-21 levels predict response to 5-fluorouracil in patients with pancreatic cancer. J Surg Oncol. 2014; 110:952-9.

36. Ferracin M, Lupini L, Salamon I, Saccenti E, Zanzi MV, Rocchi A, Da Ros L, Zagatti B, Musa G, Bassi C, Mangolini A, Cavallesco G, Frassoldati A et al. Absolute quantification of cell-free microRNAs in cancer patients. Oncotarget. 2015; 6:14545-55. doi: 10.18632/oncotarget.3859.

37. Braconi C, Valeri N, Kogure T, Gasparini P, Huang N, Nuovo GJ, Terracciano L, Croce CM, Patel T.Expression and functional role of a transcribed noncoding RNA with an ultraconserved element in hepatocellular carcinoma. Proc Natl Acad Sci USA. 2011; 10:786-91. 